\title{
Characterization of Unknown Brominated Disinfection Byproducts during Chlorination Using Ultrahigh Resolution Mass Spectrometry
}

Haifeng Zhang, ${ }^{\dagger}$ Yahe Zhang, ${ }^{\ddagger}$ Quan Shi, ${ }^{\ddagger}$ Hongdie Zheng, ${ }^{\dagger, \S}$ and Min Yang ${ }^{\dagger} *$

${ }^{\dagger}$ State Key Laboratory of Environmental Aquatic Chemistry, Research Center for Eco-Environmental Sciences, Chinese Academy of Sciences, Beijing 100085, China

${ }^{\ddagger}$ State Key Laboratory of Heavy Oil Processing, China University of Petroleum, Beijing 102249, China

${ }^{\S}$ College of Geosciences, China University of Petroleum, Beijing 102249, China

Supporting Information

ABSTRACT: Brominated disinfection byproducts (Br-DBPs), formed from the reaction of disinfectant(s) with natural organic matter in the presence of bromide in raw water, are generally more cytotoxic and genotoxic than their chlorinated analogues. To date, only a few Br-DBPs in drinking water have been identified, while a significant portion of Br-DBPs in drinking water is still unknown. In this study, negative ion electrospray ionization ultrahigh resolution Fourier transform ion cyclotron resonance mass spectrometry (ESI FT-ICR MS) was used to characterize unknown Br-DBPs in artificial drinking water. In total, 441 formulas for one-bromine-containing products and 37 formulas for two-bromine-containing products, most of which had not been previously reported, were detected in the chlorinated sample. Most Br-DBPs have corresponding chlorine-containing analogues with identical $\mathrm{CHO}$ composition. In addition, on-resonance collisioninduced dissociation (CID) of single ultrahigh resolved bromine containing mass peaks was performed in the ICR cell to isolate single bromine-containing components in a very complex natural organic matter spectrum and provide structure information. Relatively abundant neutral loss of $\mathrm{CO}_{2}$ was observed in MS-MS spectra, indicating that the unknown Br-DBPs are rich in carboxyl groups. The results demonstrate that the ESI FT-ICR MS method could provide valuable molecular composition and structure information on unknown Br-DBPs.

\section{INTRODUCTION}

During disinfection treatment of drinking water, naturally occurring bromide present in source water can be rapidly oxidized by chlorine to hypobromous acid ( $\mathrm{HOBr}$ ), which has been noted to be more powerful in reacting with natural organic matter (NOM) to form disinfection byproducts (DBPs) than hypochlorous acid $(\mathrm{HOCl}) \cdot{ }^{1-3}$ Toxicological studies have shown that brominated DBPs (Br-DBPs) are generally more cytotoxic and genotoxic than their chlorinated analogues. $^{4-7}$ For example, bacterial studies have shown that bromoacetic acid is approximately 20 times more cytotoxic and 200 times more mutagenic in Salmonella typhimurium strain TA100 than chloroacetic acid. ${ }^{6}$ Mammalian cell studies have shown that bromoacetic acid is 90 times more cytotoxic and 25 times more genotoxic in Chinese hamster ovary cells than chloroacetic acid. ${ }^{6}$ Identifying and controlling Br-DBPs have thus been important issues in securing drinking water safety.

To date, approximately $110 \mathrm{Br}-\mathrm{DBP}$ s have been reported as drinking water DBPs, most of which were identified by gas chromatography/mass spectrometry (GC-MS) with or without derivatization. ${ }^{6,8-10}$ Even with derivatization, however, GC-MS generally is not amenable to the detection of polar/ highly polar Br-DBPs. Zhang et al. ${ }^{11}$ have recently developed the precursor ion scan (PIS) method using electrospray ionization-triple quadrupole mass spectrometry (ESI-tqMS) for fast selective detection of polar/highly polar Br-DBPs. In this method, precursor ion scans of $m / z 79$ and 81 were used to selectively detect the Br-DBPs, and product ion scans were then performed to confirm the presence of bromine and provide structure information. Although many polar/highly polar BrDBPs were successfully detected and identified in artificial and actual drinking water samples, one problem related to this method is that the unit mass resolution is too low to allow nominally isobaric ions to be mass-resolved. Because of the extremely complex nature of NOM, molecular ions of NOM and their chlorinated (or brominated) products could be present at almost every nominal mass, and mass differences of isobaric ions of NOM and chlorinated (or brominated) DBPs could be as low as $36.4 \mathrm{mDa}, 15.3 \mathrm{mDa}$, or even lower (as shown in the Supporting Information, Table S1). ${ }^{12,13}$ Therefore, unit resolution product ion scans may include several isobaric parent ions and bias the compositional interpretation of single brominated compounds.

On the other hand, ultrahigh resolution Fourier transform ion cyclotron resonance mass spectrometry (FT-ICR MS) is an

Received: August 14, 2013

Revised: February 18, 2014

Accepted: February 25, 2014

Published: February 25, 2014 
emerging technique to determine the molecular composition of NOM $^{12-20}$ and chlorinated DBPs. ${ }^{12,13,20}$ The ultrahigh resolution and mass accuracy of FT-ICR MS provides molecular masses accurate to within $1 \mathrm{ppm}$, which often enables the determination of molecular formulas by mass measurement alone. ${ }^{14,15,21}$ In our previous studies, molecular formulas of chlorine-containing DBPs have been identified with negative ion electrospray ionization (ESI) FT-ICR MS in both artificial and actual drinking water samples. ${ }^{12,13}$ It is thus anticipated that the ESI FT-ICR MS method could also be suitable for detecting unknown polar Br-DBPs and identifying their molecular formulas. Furthermore, on-resonance collisioninduced dissociation (CID) of single ultrahigh resolved mass peaks in the ICR cell allows us to perform MS-MS fragmentation of Br-DBP with identical mass formulas, ${ }^{22}$ which could help in better proposing structures of unknown Br-DBPs in a very complex NOM matrix.

The main objective of this study was to characterize unknown Br-DBPs in artificial drinking water using FT-ICR MS. In addition, MS-MS fragmentation of single Br-DBPs with identical mass formulas was performed using CID FT-ICR MS. The FT-ICR MS method developed in this study may facilitate the characterization of structurally complicated halogenated DBPs, and the results will improve our knowledge of Br-DBPs.

\section{EXPERIMENTAL SECTION}

Materials. Suwannee River fulvic acid (SRFA) was purchased from the International Humic Substances Society. LC-MS grade methanol and p.a. grade hydrochloric acid were purchased from Merck (Darmstadt, Germany). Hypochlorite sodium solution (analytical grade, Sinopharm Chemical Reagent, Beijing) was diluted and used to prepare free chlorine. Ultrapure water $(18.2 \mathrm{M} \Omega \cdot \mathrm{cm})$ was prepared by a Milli-Q purification system (Millipore, USA).

Preparation of Artificial Drinking Water Samples. Artificial drinking water samples were prepared with ultrapure water containing $3.0 \mathrm{mg} / \mathrm{L}$ SRFA (as C), $90.0 \mathrm{mg} / \mathrm{L} \mathrm{NaHCO}_{3}$, and $2.0 \mathrm{mg} / \mathrm{L} \mathrm{NaBr}\left(\right.$ as $\mathrm{Br}^{-}$) according to Zhai and Zhang. ${ }^{23}$ Concentrations of bromide in fresh water typically range from trace amounts to about $0.5 \mathrm{mg} / \mathrm{L},{ }^{24}$ with the highest natural level of $\sim 2 \mathrm{mg} / \mathrm{L}$ present in Israel's source water. ${ }^{25}$ A nationwide survey of bromide ion concentrations in drinking water sources in the U.S. has shown that the overall average bromide level in random samples was between 60 and $65 \mu \mathrm{g} / \mathrm{L}$, with a range of 2 to $429 \mu \mathrm{g} / \mathrm{L}^{26}$ A relatively high bromide concentration $(2 \mathrm{mg} / \mathrm{L})$ was used to amplify brominated DBPs so that unknown brominated DBPs could be detected and identified by the FTICR MS method. Bromide at such a high level $(2 \mathrm{mg} / \mathrm{L})$ has also been used to amplify and observe the possible brominated DBPs in previous studies. ${ }^{23,25,27}$ Water samples were chlorinated in sealed 1-L amber glass bottles with a chlorine dose of $5.0 \mathrm{mg} / \mathrm{L}$ as $\mathrm{Cl}_{2}$ at $20{ }^{\circ} \mathrm{C}$ in darkness. Immediately after chlorine addition, all the samples were adjusted to $\mathrm{pH} \approx 7.5$ with $1.8 \mathrm{M}$ hydrochloric acid. The reaction was halted 5 days later by the addition of excess $\mathrm{Na}_{2} \mathrm{~S}_{2} \mathrm{O}_{3}$.

To determine whether there were any impurities in the reagents or any artifacts in the disinfection and subsequent pretreatment, control samples were generated by repeating the same procedure with samples of the aforementioned artificial water without chlorination, and chlorination control samples were generated by repeating the same chlorination procedure with artificial water samples without $\mathrm{NaBr}$.

Pretreatment of Artificial Drinking Water Samples. Procedures for water sample pretreatment were carried out according to previous studies. ${ }^{12,13}$ Briefly, water samples were acidified with hydrochloric acid to $\mathrm{pH} 2$ and pumped through a Sep-pak $\mathrm{C}_{18}$ solid-phase extraction cartridge $(1 \mathrm{~g}, 6 \mathrm{~mL})$ (Waters, USA) at a flow rate of $\sim 5 \mathrm{~mL} / \mathrm{min}$. The cartridges had been previously rinsed with methanol and acidified $(\mathrm{pH} 2)$ ultrapure water. For complete removal of salt, the cartridges were rinsed with $20 \mathrm{~mL}$ of acidified ultrapure water before elution. Immediately after extraction, each cartridge was eluted with $30 \mathrm{~mL}$ of methanol. The eluted samples were freeze-dried and stored at $-18{ }^{\circ} \mathrm{C}$ in the dark. The artificial drinking water sample composition and treatment applied are summarized in the Supporting Information, Table S2.

FT-ICR MS. The MS analyses were performed using a Bruker apex ultra FT-ICR MS equipped with a $9.4 \mathrm{~T}$ superconducting magnet. Sample extract was dissolved in methanol and injected into the electrospray source at $180 \mu \mathrm{L} / \mathrm{h}$ using a syringe pump. The operating conditions for negative ion formation consisted of a $4.0 \mathrm{kV}$ emitter voltage, $4.5 \mathrm{kV}$ capillary column introduce voltage, and $-320 \mathrm{~V}$ capillary column end voltage. Ions accumulated in the ion source for 0.1 $\mathrm{s}$ in a hexapole. All of the ions passed through a quadrupole and accumulated in an argon filled hexapole collision pool, in which ions accumulated for $1 \mathrm{~s}$. The delay was set to $1.2 \mathrm{~ms}$ to transfer the ions from the collision pool to an ICR cell by electrostatic focusing of transfer optics. The mass range was set at $\mathrm{m} / \mathrm{z} 150-$ 800 . The data size was set to $4 \mathrm{M}$ words, and the time-domain data sets were coadded with 256 acquisitions.

MS-MS Analysis. The MS-MS analysis was performed according to a previous fragmentation study of NOM. ${ }^{22}$ Briefly, the selected precursor masses were preisolated with an external quadrupole (window of 20 mass units) and stored in a collision cell consisting of a hexapole for continuous accumulation of selective ions (CASI) for $1 \mathrm{~s}$ to increase the $\mathrm{S} / \mathrm{N}$ of the parent ion. These preselected ions were transferred to the ICR cell and isolated with a $1 \mathrm{Da}$ window applying correlated harmonic excitation field (CHEF) isolation. With the exception of the target ion for fragmentation, all the remaining mass peaks were ejected out of the ICR cell by single shots. With this technique, ions are excited with their resonance frequency using a long and, therefore, sharp pulse of 10-20 ms. Very narrow excitation pulses are needed to avoid the excitation of other ions close to the target ions. Nitrogen was pulsed into the ICR cell to a final pressure of about $10^{-7} \mathrm{mbar}$ in the analyzer cell. The isolated parent masses were excited with their resonance frequency for $400 \mu$ s using a peak-to-peak voltage of 3-5 V. A pump delay of $3 \mathrm{~s}$ was applied to regain a lower pressure $\left(\sim 10^{-10} \mathrm{mbar}\right)$ prior to mass detection. The ions were then excited with a frequency sweep and detected for about $0.55 \mathrm{~s}$ in the mass range $\mathrm{m} / \mathrm{z}$ 120-500. The size of the acquired data set was $1 \mathrm{M}$ words for MS-MS spectra. The mass accuracy of the parent and fragment ions was within $1 \mathrm{ppm}$. The data were zero filled once before sine apodization; 256 scans were added for one mass spectrum.

Mass Calibration and Data Analysis. The FT-ICR mass spectra were externally calibrated for a mass range of 150-800 using a sodium formate aqueous solution and internally recalibrated with a known homologous series of the NOM sample. ${ }^{12,13}$ Elemental compositions were assigned from the $m$ / $z$ peaks by a mass calculator program ${ }^{12,13}$ limited to molecular formulas consisting of up to $100{ }^{12} \mathrm{C}, 2{ }^{13} \mathrm{C}, 200{ }^{1} \mathrm{H}, 3{ }^{14} \mathrm{~N}, 30$ 


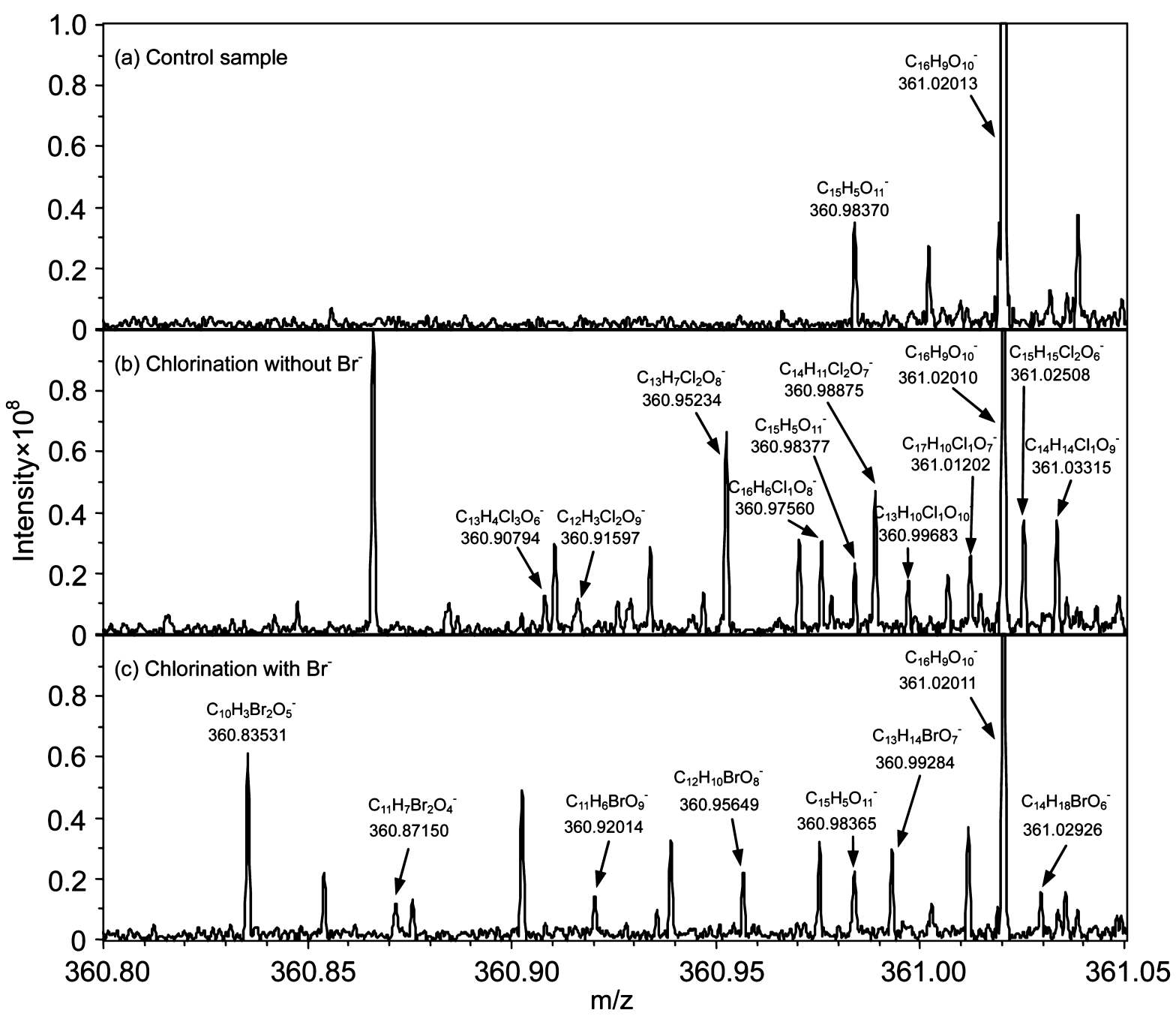

Figure 1. Negative-ion ESI FT-ICR mass spectra for bromine-containing products at nominal mass 361: (a) control sample without chlorination, (b) chlorination control sample without $\mathrm{Br}^{-}$, and (c) chlorination water sample with $\mathrm{Br}^{-}$.

${ }^{16} \mathrm{O}, 1{ }^{32} \mathrm{~S}, 3{ }^{35} \mathrm{Cl}$, and $3{ }^{79} \mathrm{Br}$ atoms. All assigned formulas must meet basic chemical criteria: ${ }^{28}$ (1) the number of $\mathrm{H}$ atoms must be at least $1 / 3$ the number of $\mathrm{C}$ atoms and cannot exceed $2 \mathrm{C}+$ $\mathrm{N}+2$; (2) the sum of $\mathrm{H}$ and $\mathrm{N}$ atoms must be even (the "nitrogen rule"); and (3) the number of $\mathrm{N}$ or $\mathrm{O}$ atoms cannot exceed the number of $\mathrm{C}$ atoms. Halogens $(\mathrm{Cl}, \mathrm{Br})$ are treated like $\mathrm{H}$ atoms. These criteria ensure that the formulas generated can at least chemically exist. Additionally, molecular formulas of chlorine-containing peaks and bromine-containing peaks were cross validated using the ${ }^{37} \mathrm{Cl}$ isotopomer and ${ }^{81} \mathrm{Br}$ isotopomer, respectively. Because the focus of this paper was on characterization of unknown Br-DBPs, only molecular formulas containing $\mathrm{C}, \mathrm{H}, \mathrm{O}, \mathrm{Cl}$, and $\mathrm{C}, \mathrm{H}, \mathrm{O}, \mathrm{Br}$ were further investigated.

Limitations. It should be noted that, in this study, $\mathrm{C}_{18}$ solid phase extraction (SPE) was used to isolate and concentrate the analyte from samples and for desalting because ESI FT-ICR MS analysis requires salt-free samples. Only molecules that can be adsorbed on $\mathrm{C}_{18}$ and desorbed by an organic solvent were analyzed by mass spectrometry. Highly hydrophilic (incomplete adsorption) or highly hydrophobic (incomplete desorption) molecules were not considered. During the ESI process, the newly formed halogen-containing components may compete with the original NOM components. Some of the changes in relative peak abundances may be due to increased ion suppression and/or signal enhancement caused by the additional complexity added by the newly formed halogencontaining components. In addition, the FT-ICR MS used in this study has a mass cutoff at $150 \mathrm{Da}$. Therefore, this study mainly characterized the $\mathrm{C}_{18}$ extractable Br-DBP molecules, and the detected formulas do not represent the entire pool of $\mathrm{Br}$ DBPs formed after chlorination. On the other hand, although the molecular formulas of Br-DBPs were assigned using the ultrahigh FTICR MS data, each identified formula could represent a variety of different structural isomers.

\section{RESULTS AND DISCUSSION}

Detection of Br-DBPs. In our previous studies, ${ }^{12,13}$ FTICR MS was successfully used to characterize chlorinated DBPs in drinking water. In this study, with a similar FT-ICR MS method, many Br-DBPs were detected in artificial $\mathrm{Br}^{-}$ containing drinking water after chlorination. Figure 1 shows close-up views of expanded mass spectra at the nominal mass $m / z 361$, as an example. Newly formed Br-DBPs were clearly observed in the mass spectrum (Figure 1c). Similar to the previously detected chlorinated DBPs, ${ }^{12,13} \mathrm{Br}$-DBPs also have a characteristic mass difference of $36.4 \mathrm{mDa}$ for the replacement of $\mathrm{O}$ by $\mathrm{CH}_{4}$. In total, molecular formulas of 441 peaks 
containing one bromine and 37 peaks containing two bromines were identified in this study.

An approach for examining molecules that differ from each other only in number of $\mathrm{CH}_{2}$ groups (i.e., members of homologous series) is Kendrick mass defect analysis. ${ }^{14,29-31}$ The Kendrick mass is based on assigning the mass of $\mathrm{CH}_{2}$ to be 14.0000 Da instead of the IUPAC $14.01565 \mathrm{Da}$. The IUPAC mass of a molecule is converted to Kendrick mass (KM) according to eq $1^{14,29-31}$

$$
\mathrm{KM}=\mathrm{IUPAC} \text { mass }_{\text {measured }}[14.0000 / 14.01565]
$$

The Kendrick mass defect (KMD) is the difference between the nominal IUPAC mass (NM) and the accurate KM (eq $2)^{29-31}$ All members of a homologous series of molecules differing only in the number of $\mathrm{CH}_{2}$ groups have the same KMD value.

$$
\mathrm{KMD}=[\mathrm{NM}-\mathrm{KM}]
$$

Because it is possible for different homologous series to have very similar KMDs, it is necessary to presort the ions based on

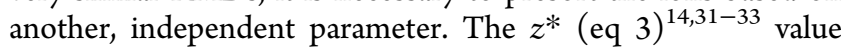
has been shown to be a useful parameter for presorting homologous series of fulvic acids. In eq 3 , the modulus is the remainder of the division of nominal mass by 14 . Figure 2 panels $\mathrm{a}$ and $\mathrm{b}$ show the KMD analysis of formulas containing one bromine and formulas containing two bromines,

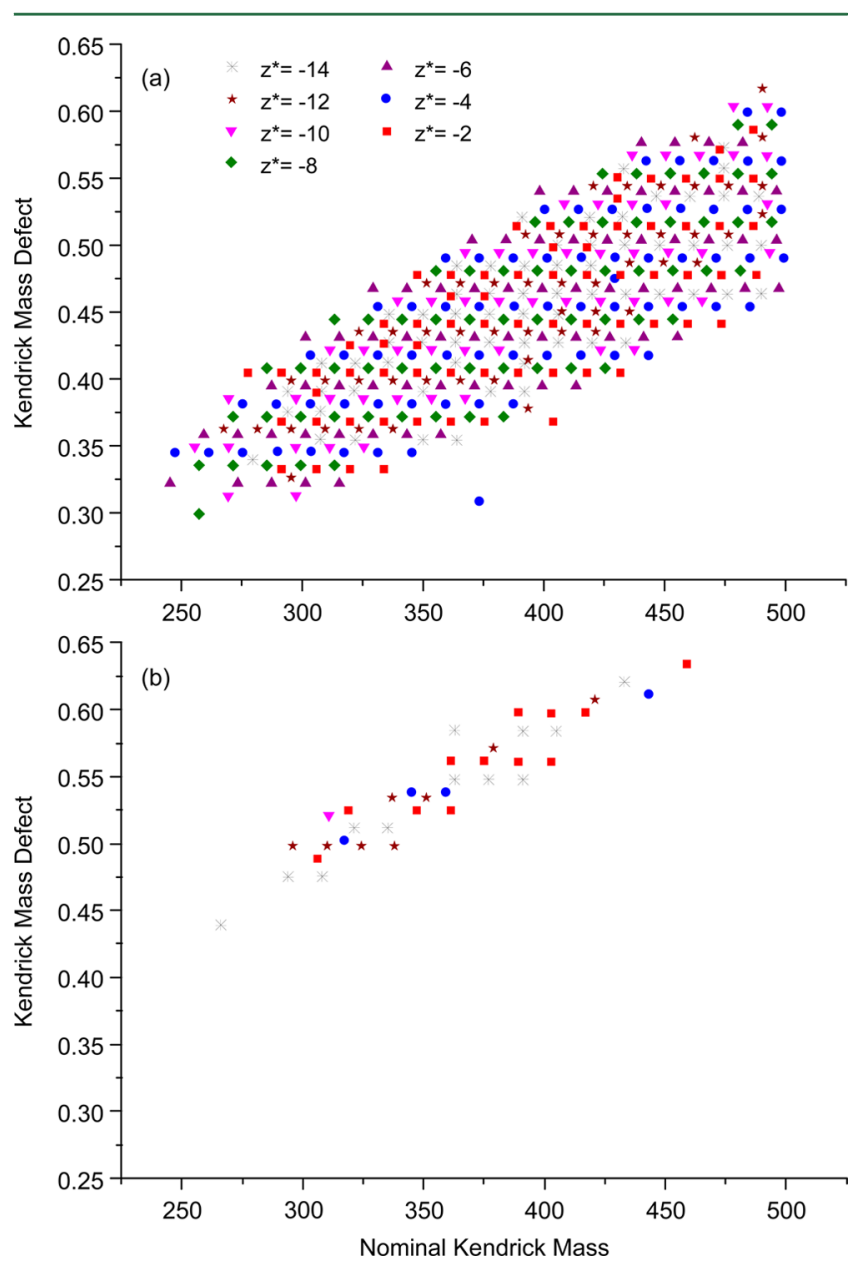

Figure 2. Kendrick mass defect analysis with $z^{*}$ of (a) one-brominecontaining formulas and (b) two-bromine-containing formulas. respectively. The bromine-containing formulas can be sorted out into a homologous series based on KMD analysis and $\mathrm{z}^{*}$, suggesting they may arise from homologous series of parent NOM components.

$$
\mathrm{z}^{*}=(\operatorname{modulus}[\mathrm{NM} / 14])-14
$$

Another widely used tool for the visualization of FT-ICR MS data is the van Krevelen diagram, in which individual molecular formulas are plotted on the basis of their molar $\mathrm{H} / \mathrm{C}$ and $\mathrm{O} / \mathrm{C}$ ratios. $^{31,34}$ Each dot in the diagram represents one or more molecular formulas with a specific $\mathrm{O} / \mathrm{C}$ and $\mathrm{H} / \mathrm{C}$ ratio. The types of formulas (for example, lignin and tannin, etc.) can be classified based on their locations in the van Krevelen diagram. ${ }^{17,31,35,36}$ The stoichiometric ranges used to establish boundaries of the classification in such (van Krevelen) diagrams for the components found in NOM are quite variable in the literature. ${ }^{36}$ Figure 3 panels $\mathrm{d}$ and e show the van Krevelen diagrams of the one-bromine-containing DBPs and twobromine-containing DBPs in the chlorinated artificial water fortified with $\mathrm{Br}^{-}$, respectively. Detailed molecular formulas for these Br-DBPs are listed in the Supporting Information, Table S3. All assigned $\mathrm{CHO}, \mathrm{CHOCl}$, and $\mathrm{CHOBr}$ formulas are available in a spreadsheet file in the Supporting Information for download.

Comparison of Patterns of Br-DBPs and Cl-DBPs. All $478 \mathrm{Br}$-DBPs identified in this study were compared to the chlorinated components identified in the chlorination control sample, which were generated by repeating the same chlorination procedure with an artificial water sample without $\mathrm{NaBr}$. In total, 684 formulas of one-chlorine-containing components, 495 formulas of two-chlorine-containing components, and 191 formulas of three-chlorine-containing components were identified in the chlorination control samples. Detailed molecular formulas for these chlorine-containing components are listed in the Supporting Information, Table S4. Among the 441 one-bromine-containing DBPs, 392 of them have corresponding one-chlorine-containing analogues (which have identical $\mathrm{CHO}$ composition). Among the 37 twobromine-containing DBPs, 28 have corresponding twochlorine-containing analogues. Figure 3 shows the comparison of the distribution patterns for the Br-DBPs and chlorinecontaining components.

It should be noted that in this study, 74 formulas of onechlorine-containing components (Supporting Information, Table S5) were also identified in the control sample (artificial water samples without chlorination). Among the 74 formulas of chlorine-containing organic components, 63 overlapped with the "already present" chlorine-containing formulas listed in the drinking water DBPs study by Lavonen et al. ${ }^{20}$ Lavonen and colleagues developed a classification method for differentiating formulas of chlorine-containing DBPs from "already present" chlorine-containing formulas (which are present before disinfection). ${ }^{20}$ They suggested that the "already present" chlorine-containing formulas should not be considered as DBPs. However, in this study we observed that, compared to the SRFA control sample, the peak intensities of the already present chlorine-containing components increased 4 to 18 times after chlorination (Supporting Information, Figure S1, S2). Furthermore, all of the 74 already present chlorinecontaining formulas have corresponding bromine-containing analogues. Since no bromine-containing formulas were identified in the control sample, it is reasonable to deduce that the already present chlorine-containing formulas could also 

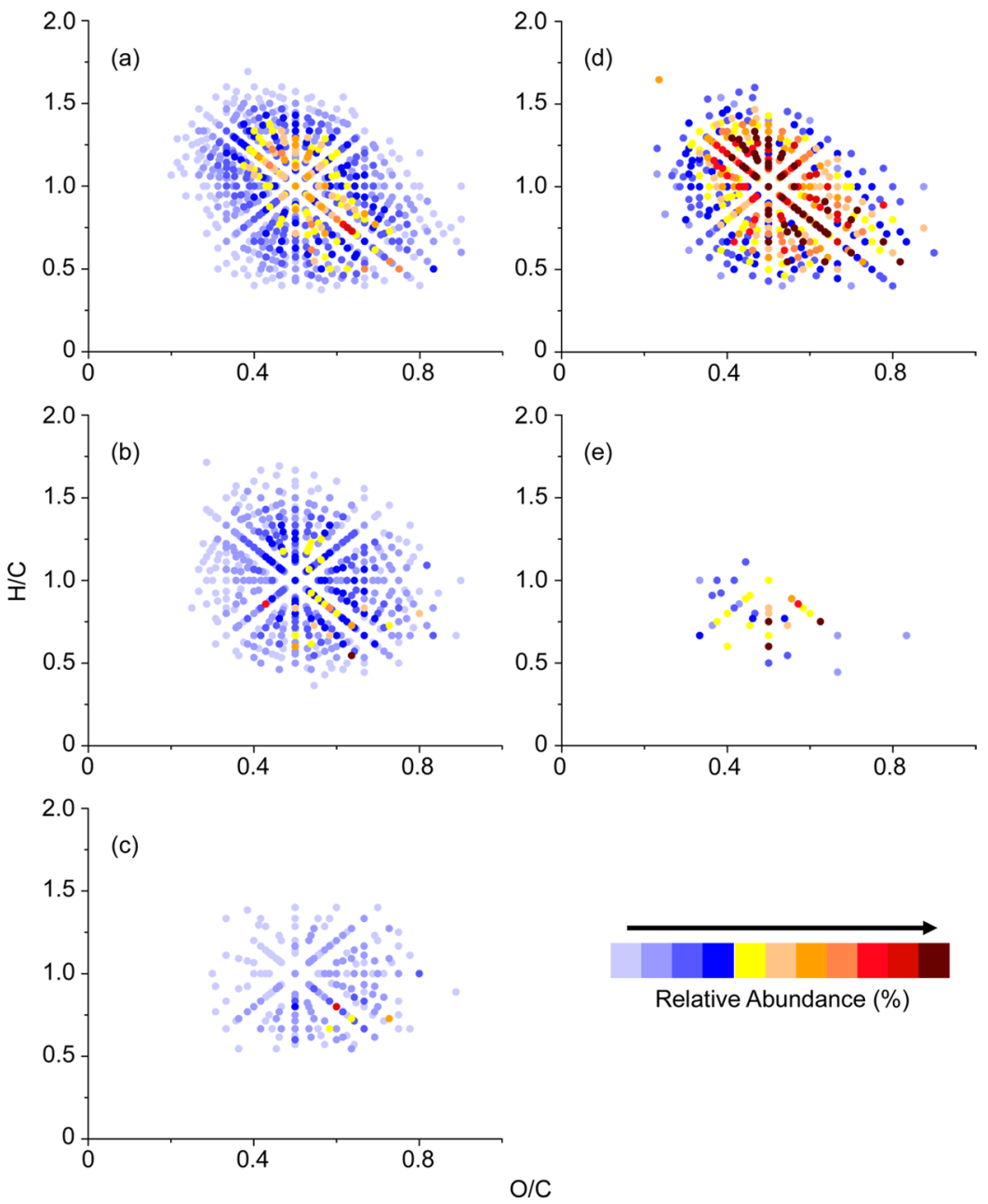

Figure 3. van Krevelen diagram of chlorinated components and brominated components identified in chlorination SRFA samples without and with $\mathrm{NaBr}$, respectively: (a) one-chlorine-containing, (b) two-chlorine-containing, and (c) three-chlorine-containing components in chlorination SRFA samples without $\mathrm{NaBr}$; (d) one-bromine-containing, and (e) two-bromine-containing components in chlorination SRFA samples with NaBr. Color bar represents the relative abundance of a formula.

be formed during chlorination as DBPs. All of this shows that further study to clarify the relationship of "already present" chlorine-containing components and DBPs is still needed.

MS-MS Analysis. On-resonance CID MS-MS experiment was performed to facilitate proposal of possible structures for unknown Br-DBPs. Single parent ions of Br-DBPs were selected and isolated for fragmentation analysis. The parent masses were isolated maintaining $>70 \%$ of the precursor ion intensity. Figure 4 panels a and b show the MS-MS spectra of the parent mass at $m / z 276.899$ and 360.835 , which correspond to molecular ions of the one-bromine-containing molecule $\left(\mathrm{C}_{7} \mathrm{H}_{3} \mathrm{BrO}_{7}\right)$ and two-bromine-containing molecule $\left(\mathrm{C}_{10} \mathrm{H}_{4} \mathrm{Br}_{2} \mathrm{O}_{5}\right)$, respectively. Series of neutral loss of $\mathrm{CO}_{2}$ were observed in both spectra (Figure 4a,b). The observation of decarboxylation is in agreement with previous fragmentation studies of fulvic acid. ${ }^{14,22,37}$ However, losses of $\mathrm{H}_{2} \mathrm{O}, \mathrm{CO}$, or $\mathrm{CH}_{4}$, which have been previously reported in MS-MS analysis of fulvic acid, ${ }^{14,22}$ were not observed. This difference may be attributed to the differences in the structures of the precursor ions. For example, These et al. ${ }^{38}$ observed different types of fragment ions for three isobaric ions of fulvic acid at nominal mass 297 in an MS-MS study. They observed loss of $\mathrm{CO}_{2}$ alone for precursor ion $\mathrm{C}_{13} \mathrm{H}_{13} \mathrm{O}_{8}{ }^{-}$, losses of $\mathrm{CO}_{2}$ and $\mathrm{CO}_{2}$ plus $\mathrm{H}_{2} \mathrm{O}$ for precursor ion $\mathrm{C}_{14} \mathrm{H}_{17} \mathrm{O}_{7}^{-}$, and losses of $\mathrm{CO}_{2}, \mathrm{H}_{2} \mathrm{O}$, and
$\mathrm{CO}_{2}$ plus $\mathrm{H}_{2} \mathrm{O}$ for precursor ion $\mathrm{C}_{15} \mathrm{H}_{21} \mathrm{O}_{6}^{-}$, respectively. Previous investigations have shown that the fulvic acid molecules detected by ESI-MS are dominated by carboxylate moieties with a limited number of hydroxy groups. $22,33,37,38 \mathrm{In}$ addition, it was previously suggested that in the course of oxidative alteration of very diverse source materials of fulvic acid, all functional groups that can be hydrolyzed will be hydrolyzed, erasing functional groups such as ethers, esters, and lactones. ${ }^{33}$ With this knowledge, the observation of decarboxylation suggested that most likely carboxyl groups are present in the molecular structure of these Br-DBP molecules.

On the basis of the fragmentation patterns, possible structures can be assigned. Possible molecular structures that are in agreement with the observed fragments are shown in Figure 4 panels $a$ and $b$, respectively. It should be noted that the fragmentation of the proposed structures shown in Figure 4a,b is only an example. Since one molecular formula can represent a multitude of different structural isomers, the fragmentation pattern can also be a result of a mixture of several isomers. Nevertheless, the combination of the exact mass and fragmentation patterns could provide valuable information regarding the possible molecular moieties of Br-DBPs.

Comparison with Br-DBPs Detected Previously. Richardson compiled a review on drinking water DBPs in 

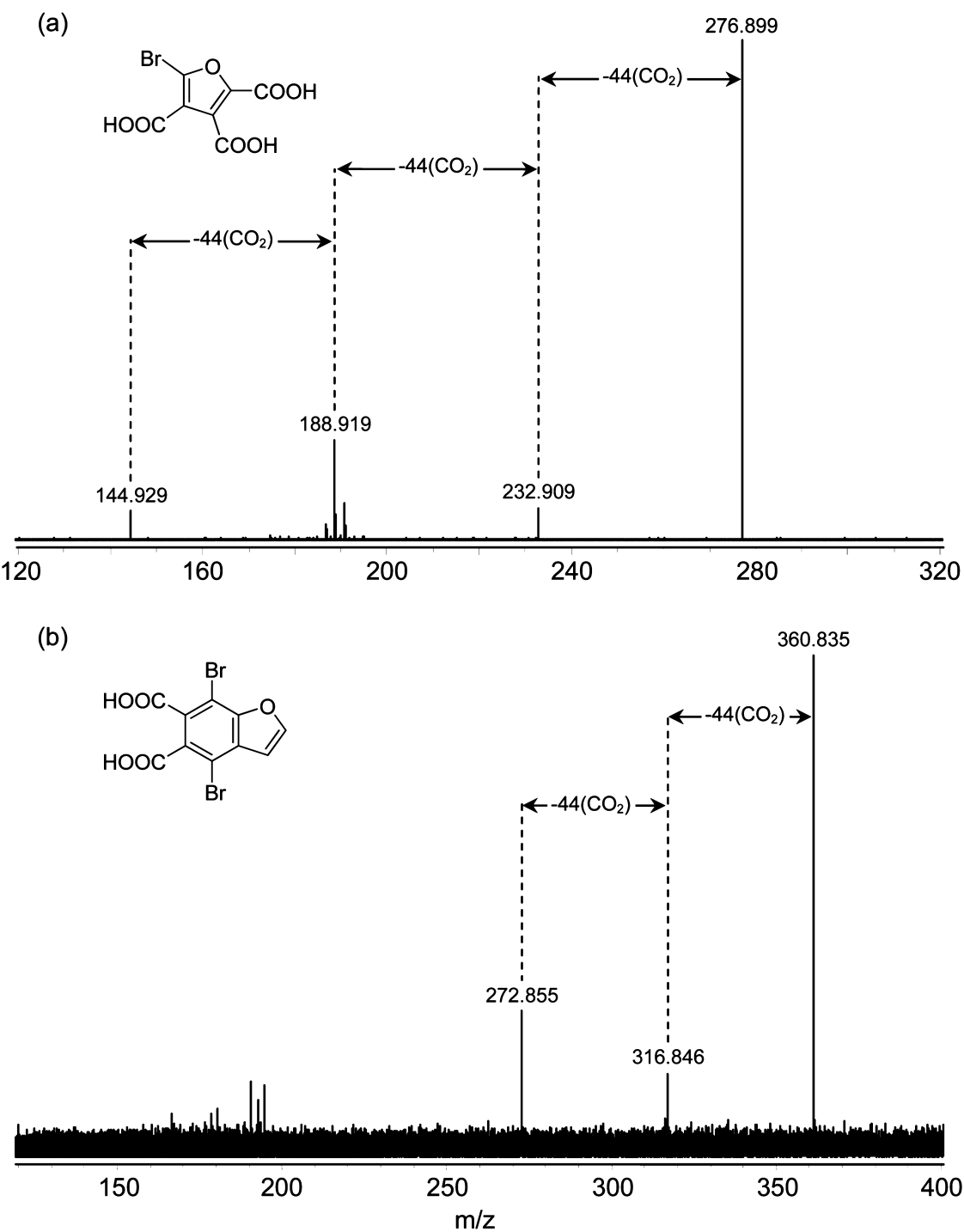

Figure 4. In-cell CID fragmentation spectra of the parent ion at $m / z$ (a) $276.899\left(\mathrm{C}_{7} \mathrm{H}_{2} \mathrm{BrO}_{7}^{-}\right)$and (b) $360.835\left(\mathrm{C}_{10} \mathrm{H}_{3} \mathrm{Br}_{2} \mathrm{O}_{5}{ }^{-}\right)$with annotation of fragment losses and proposed structures.

which she listed approximately 600 chlorination DBPs, among which 110 compounds contain at least one bromine atom, and almost all of them were identified by gas chromatography/mass spectrometry (GC-MS) or derivatization-GC/MS., ${ }^{6-10}$ There was no match between Br-DBPs observed in this study and those listed by Richardson. The Br-DBPs detected in this study fall in a molecular mass range from 200 to $500 \mathrm{Da}$, and may be rich in carboxyl groups, which make these polar Br-DBPs suitable for analysis with negative ion ESI-MS. Recently, Zhang et al. ${ }^{11}$ successfully developed the PIS method using ESI-tqMS for fast selective detection of polar Br-DBPs and studied the formation of new and unknown Br-DBPs during chlorination. ${ }^{23}$ They detected 38 ion clusters of possible Br-DBPs, five of which were confirmed or proposed as brominated acetic acids, 11 could be confirmed or proposed to be identified chemical structures, and 22 were bromine-containing compounds with unknown molecular formula. Because their samples were prepared using a liquid-liquid extraction method and the formulas of most of Br-DBPs in their study are not available, a comprehensive comparison was difficult. When comparing only the formulas they confirmed or proposed, five of the 11 formulas with proposed chemical structures could be found in the list of this study. Brominated acetic acids were not found in this study. This could possibly be caused by the limitations of the SPE method adopted in this study, because the highly polar brominated acids were not recovered by the nonpolar $\mathrm{C} 18$ stationary phase.

In total, $473 \mathrm{Br}$-DBPs with identified molecular formulas were for the first time reported in this study. Our results demonstrated that ESI FT-ICR MS is a powerful tool for the detection of the Br-DBPs, and the combination of the exact mass and MS-MS fragmentation could provide valuable molecular composition and structure information on $\mathrm{Br}$ DBPs. Further work with offline or online chromatographic preseparation, which could help to separate molecules with identical mass formulas and different molecular structures, will be needed to supply additional structure information and improve our knowledge on the unknown Br-DBPs.

\section{ASSOCIATED CONTENT}

\section{S Supporting Information}

Additional figures and tables as well as formulas for Br-DBPs and chlorinated components noted in the text. This material is available free of charge via the Internet at http://pubs.acs.org. 


\section{AUTHOR INFORMATION}

\section{Corresponding Author}

*Phone: +86-10-62923475; fax: +86-10-62923541; e-mail: yangmin@rcees.ac.cn.

\section{Notes}

The authors declare no competing financial interest.

\section{ACKNOWLEDGMENTS}

This work was supported by the National Natural Science Foundation of China (Grant Nos. 21377150, 50938007, and 51221892).

\section{REFERENCES}

(1) Morris, J. C. The chemistry of aqueous chlorine in relation to water chlorination. In Water Chlorination: Environmental Impact and Health Effects; Jolley, R. L., Ed.; Ann Arbor Science: Ann Arbor, MI, 1978; Vol. 1, pp21-35.

(2) Symons, J. M.; Krasner, S. W.; Simms, L. A.; Sclimenti, M. Measurement of THM and precursor concentrations revisited: The effect of bromide ion. J. Am. Water Works Assoc. 1993, 85, 51-62.

(3) Cowman, G. A.; Singer, P. C. Effect of bromide ion on haloacetic acid speciation resulting from chlorination and chloramination of aquatic humic substances. Environ. Sci. Technol. 1996, 30, 16-24.

(4) Plewa, M. J.; Kargalioglu, Y.; Vankerk, D.; Minear, R. A.; Wagner, E. D. Mammalian cell cytotoxicity and genotoxicity analysis of drinking water disinfection by-products. Environ. Mol. Mutagen. 2002, 40, 134.

(5) Echigo, S.; Itoh, S.; Natsui, T.; Araki, T.; Ando, R. Contribution of brominated organic disinfection by-products to the mutagenicity of drinking water. Water Sci. Technol. 2004, 50, 321-328.

(6) Richardson, S. D.; Plewa, M. J.; Wagner, E. D.; Schoeny, R.; DeMarini, D. M. Occurrence, genotoxicity, and carcinogenicity of regulated and emerging disinfection byproducts in drinking water: A review and roadmap for research. Mutat. Res. 2007, 636, 178-182.

(7) Komaki, Y.; Pals, J.; Wagner, E. D.; Marinas, B. J.; Plewa, M. J. Mammalian cell DNA damage and repair kinetics of monohaloacetic acid drinking water disinfection by-products. Environ. Sci. Technol. 2009, 43, 8437-8442.

(8) Richardson, S. D. Drinking water disinfection by-products. In Encyclopedia of Environmental Analysis and Remediation; John Wiley \& Sons: New York, 1998; pp 1398-1421.

(9) Richardson, S. D., Jr.; Rav-Acha, C.; Groisman, L.; Popilevsky, I.; Juraev, O.; Glezer, V.; Mckague, A. B.; Plewa, M. J.; Wagner, E. D. Tribromopyrrole, brominated acids, and other disinfection byproducts produced by disinfection of drinking water rich in bromide. Environ. Sci. Technol. 2003, 37, 3782-3793.

(10) Krasner, S. W.; Weinberg, H. S.; Richardson, S. D.; Pastor, S. J.; Chinn, R.; Sclimenti, M. J.; Onstad, G. D.; Thruston, A. D., Jr. Occurrence of a new generation of disinfection byproducts. Environ. Sci. Technol. 2006, 40, 7175-7185.

(11) Zhang, X. R.; Talley, J. W.; Boggess, B.; Ding, G. Y.; Birdsell, D. Fast selective detection of polar brominated disinfection byproducts in drinking water using PISs. Environ. Sci. Technol. 2008, 42, 6598-6603.

(12) Zhang, H.; Zhang, Y.; Shi, Q.; Ren, S.; Yu, J.; Ji, F.; Luo, W.; Yang, M. Characterization of low molecular weight dissolved natural organic matter a long the treatment trait of a waterworks using Fourier transform ion cyclotron resonance mass spectrometry. Water Res. 2012, 46, 5197-5204.

(13) Zhang, H.; Zhang, Y.; Shi, Q.; Hu, J.; Chu, M.; Yu, J.; Yang, M. Study on transformation of natural organic matter in source water during chlorination and its chlorinated products using ultrahigh resolution mass spectrometry. Environ. Sci. Technol. 2012, 46, 43964402.

(14) Stenson, A. C.; Marshall, A. G.; Cooper, W. T. Exact masses and chemical formulas of individual Suwannee river fulvic acids from ultrahigh resolution electrospray ionization Fourier transform ion cyclotron resonance mass spectra. Anal. Chem. 2003, 75, 1275-1284.
(15) Hertkorn, N.; Frommberger, M.; Witt, M.; Koch, B. P.; SchmittKopplin, Ph.; Perdue, E. M. Natural organic matter and the event horizon of mass spectrometry. Anal. Chem. 2008, 80, 8908-8919.

(16) Kim, S.; Kaplan, L. A.; Hatcher, P. G. Biodegradable dissolved organic matter in a temperate and a tropical stream determined from ultra-high resolution mass spectrometry. Limnol. Oceanogr. 2006, 51, 1054-1063.

(17) Sleighter, R. L.; Hatcher, P. G. Molecular characterization of dissolved organic matter (DOM) along a river to ocean transect of the lower Chesapeake Bay by ultrahigh resolution electrospray ionization Fourier transform ion cyclotron resonance mass spectrometry. Mar. Chem. 2008, 110, 140-152.

(18) Reemtsma, T.; These, A.; Linscheid, M.; Leenheer, J.; Spitzy, A. Molecular and structural characterization of dissolved organic matter from the deep ocean by FTICR-MS, including hydrophilic nitrogenous organic molecules. Environ. Sci. Technol. 42, 1430-1437.

(19) Llewelyn, J. M.; Landing, W. M.; Marshall, A. G.; Cooper, W. T. Electrospray ionization Fourier transform ion cyclotron resonance mass spectrometry of dissolved organic phosphorus species in a treatment wetland after selective isolation and concentration. Anal. Chem. 2002, 74, 600.

(20) Lavonen, E. E.; Gonsior, M.; Tranvik, L. J.; Schmitt-Kopplin, P.; Koehler, S. J. Selective chlorination of natural organic matter: Identification of previously unknown disinfection byproducts. Environ. Sci. Technol. 2013, 47, 2264-2271.

(21) Kim, S.; Rodgers, R. P.; Marshall, A. G. Truly "exact" mass: Elemental composition can be determined uniquely from molecular mass measurement at similar to $0.1 \mathrm{mDa}$ accuracy for molecules up to similar to 500 Da. Int. J. Mass Spectrom. 2006, 251, 260-265.

(22) Witt, M.; Fuchser, J.; Koch, B. P. Fragmentation studies of fulvic acids using collision induced dissociation Fourier transform ion cyclotron resonance mass spectrometry. Anal. Chem. 2009, 81, 26882694.

(23) Zhai, H.; Zhang, X. Formation and decomposition of new and unknown polar brominated disinfection byproducts during chlorination. Environ. Sci. Technol. 2011, 45, 2194-2201.

(24) Bromide in drinking-Water: Background Document for Development of WHO Guidelines for Drinking-Water Quality; World Health Organization: Geneva, Switzerland, 2009; http://www.who.int/entity/ water_sanitation_health/dwq/chemicals/Fourth_Edition_Bromide_ Final January 2010.pdf.

(25) Zhai, H. Y.; Zhang, X. R. A new method for differentiating adducts of common drinking water DBPs from higher molecular weight DBPs in electrospray ionization-mass spectrometry analysis. Water Res. 2009, 43, 2093-2100.

(26) Amy, G.; Siddiqui, M.; Zhai, W.;DeBroux, J.; Odem, W. Nationwide survey of bromide ion concentrations in drinking water sources. AWWA ACE93103; American Water Works Association: Denver CO, 1993.

(27) Richardson, S. D.; Thruston, A. D.; Rav-Acha, C.; Groisman, L.; Popilevsky, I.; Juraev, O.; Glezer, V.; McKague, A. B.; Plewa, M. J.; Wagner, E. D. Tribromopyrrole, brominated acids, and other disinfection byproducts produced by disinfection of drinking water rich in bromide. Environ. Sci. Technol. 2003, 37, 3782-3793.

(28) Kujawinski, E. B.; Behn, M. D. Automated analysis of electrospray ionization Fourier transform ion cyclotron resonance mass spectra of natural organic matter. Anal. Chem. 2006, 78, 43634373.

(29) Kendrick, E. A mass scale based on $\mathrm{CH}_{2}=14.0000$ for high resolution mass spectrometry of organic compounds. Anal. Chem. 1963, 35, 2146-2154.

(30) Hughey, C. A.; Hendrickson, C. L.; Rodgers, R. P.; Marshall, A. G. Kendrick mass defect spectrum: A compact visual analysis for ultrahigh-resolution broadband mass spectra. Anal. Chem. 2001, 73, 4676-4681.

(31) Kim, S.; Kramer, R. W.; Hatcher, P. G. Graphical method for analysis of ultrahigh-resolution broadband mass spectra of natural organic matter, the van Krevelen diagram. Anal. Chem. 2003, 75, $5336-5344$. 
(32) Hsu, C. S.; Qian, K.; Chen, Y. C. An innovative approach to data analysis in hydrocarbon characterization by on-line liquid chromatography-mass spectrometry. Anal. Chim. Acta 1992, 264, 79-89.

(33) Reemtsma, T.; These, A. Comparative investigation of lowmolecular-weight fulvic acids of different origin by SEC-Q-TOF-MS: New insights into structure and formation. Environ. Sci. Technol. 2005, 39, 3507-3512.

(34) van Krevelen, D. W. Graphical statistical method for the study of structure and reaction processes of coal. Fuel 1950, 19, 269-284.

(35) Schmidt, F.; Elvert, M.; Koch, B. P.; Witt, M.; Hinrichs, K. Molecular characterization of dissolved organic matter in pore water of continental shelf sediments. Geochim. Cosmochim. Acta 2009, 73, 3337-3358.

(36) Ohno, T.; He, Z.; Sleighter, R.; Honeycutt, C. W.; Hatcher, P. G. Ultra high resolution mass spectrometry and indicator species analysis to identify marker components of soil- and plant biomassderived organic matter fractions. Environ. Sci. Technol. 2010, 44, 85948600 .

(37) Reemtsma, T.; These, A.; Springer, A.; Linscheid, M. Fulvic acids as transition state of organic matter: Indications from high resolution mass spectrometry. Environ. Sci. Technol. 2006, 40, 58395845 .

(38) These, A.; Winkler, M.; Thomas, C.; Reemtsma, T. Determination of molecular formulas and structural regularities of low molecular weight fulvic acids by size-exclusion chromatography with electrospray ionization quadrupole time-of- flight mass spectrometry. Rapid Commun. Mass Spectrom. 2004, 18, 1777-1786. 